\title{
How to make an alternative plastic gown during the personal protective equipment shortage due to the COVID-19 pandemic
}

Prevention of severe acute respiratory syndrome coronavirus 2 (SARS-CoV-2) transmission has led to a shortage of personal protective equipment (PPE) since the end of 2019, when SARS-CoV-2 was identified in Wuhan, China. Quickly manufactured alternative PPE is in high demand worldwide. We show how to make an alternative long-sleeve plastic gown for use as PPE, the Toyonaka Poly Gown, using a plastic trash bag. We thank all staff and doctors at Toyonaka Municipal Hospital.

To make the garment, you need: (i) cardboard to make a pattern (length $130 \mathrm{~cm} \times$ width $100 \mathrm{~cm}$ ), (ii) a heat gun, (iii) scissors, and (iv) a 120-L plastic trash bag $(120 \mathrm{~cm} \times 100 \mathrm{~cm})$.

First, prepare the cardboard to be used for the pattern by cutting slits ("notches," width $2 \mathrm{~cm}$ ) and holes as shown in - Fig. 1. Next, place the plastic trash bag beneath the cardboard pattern. Use a magic marker to mark dots through the holes for landmarks. Then, using a heat gun, heat-weld along the slits in the cardboard pattern. After that, use scissors to cut the middle of the back of the plastic bag up to the landmark dot at $10 \mathrm{~cm}$. On either side of that cut line, cut strips (width $5 \mathrm{~cm}$ ) for the right and left waist "strings," and then cut the neck hole. Finally, cut along the center of the welded "seams" of the plastic bag to make sleeves ( $>$ Fig. 2; $>$ Video 1 ).

To wear the gown, first put your arms through the sleeves. You can spread and adjust the size of the cuff when you put your arm through the cuff. Then, put your head through the neck of the gown. Finally, tie the gown strings in the back ( Video 1 ).

Endoscopy_UCTN_Code_TTT_1AU_2AC

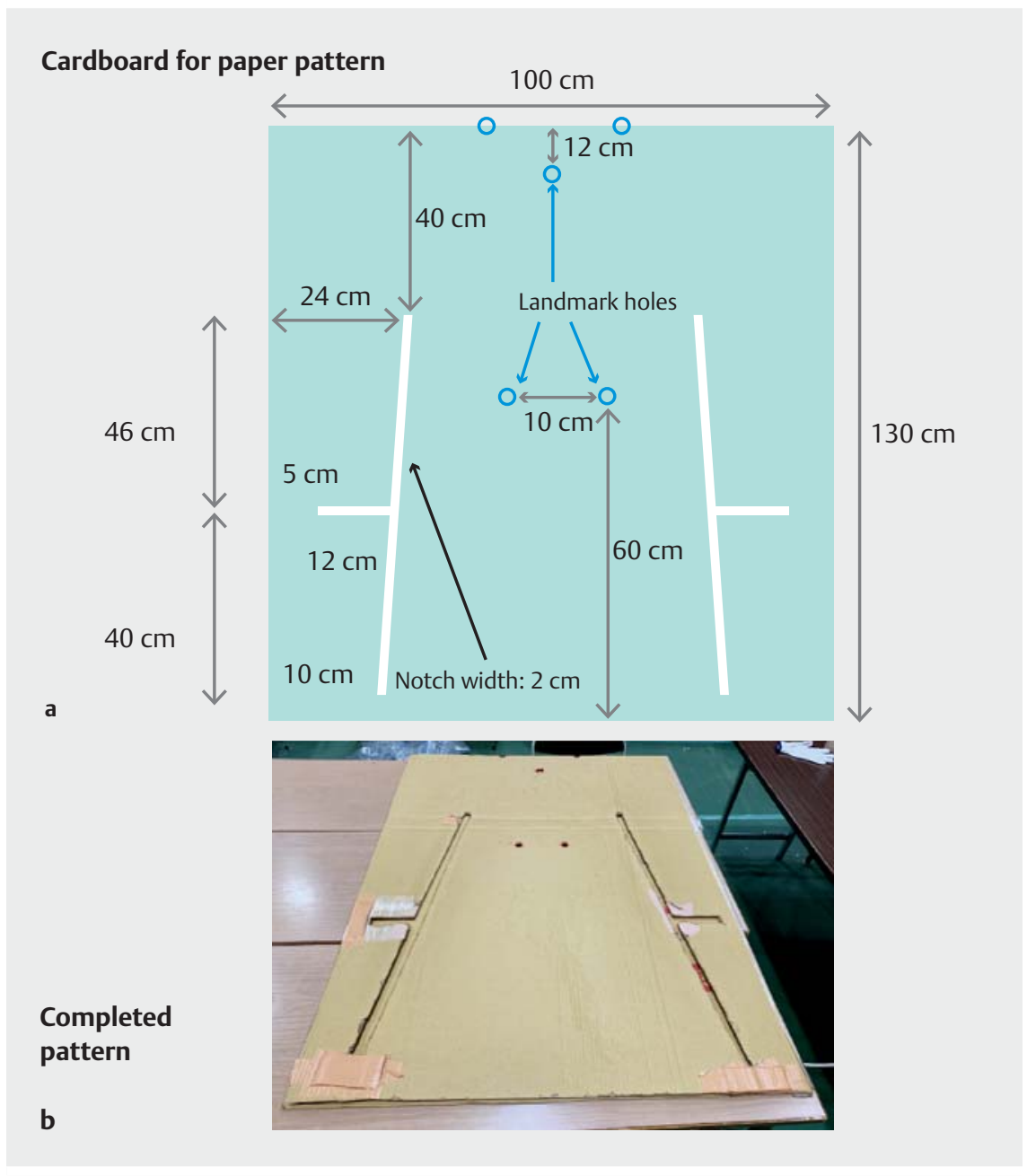

Fig. 1 a Marking out the cardboard for the pattern; b completed pattern.

\section{Competing interests}

The authors declare that they have no conflict of interest.
The authors

Tsutomu Nishida ${ }^{1}$, Norihiro Suzuki ${ }^{2}$, Yuji $\mathrm{Ono}^{2}$, Junzo Shimizu2,3, Dai Nakamatsu', Kengo Matsumoto ${ }^{1}$, Masashi Yamamoto ${ }^{1}$

1 Department of Gastroenterology, Toyonaka Municipal Hospital, Osaka, Toyonaka, Japan

2 Infection Control Office, Toyonaka Municipal Hospital, Osaka, Toyonaka, Japan

3 Department of Surgery, Toyonaka Municipal Hospital, Osaka, Toyonaka, Japan 
120 L plastic bag $(120 \times 100 \mathrm{~cm})$

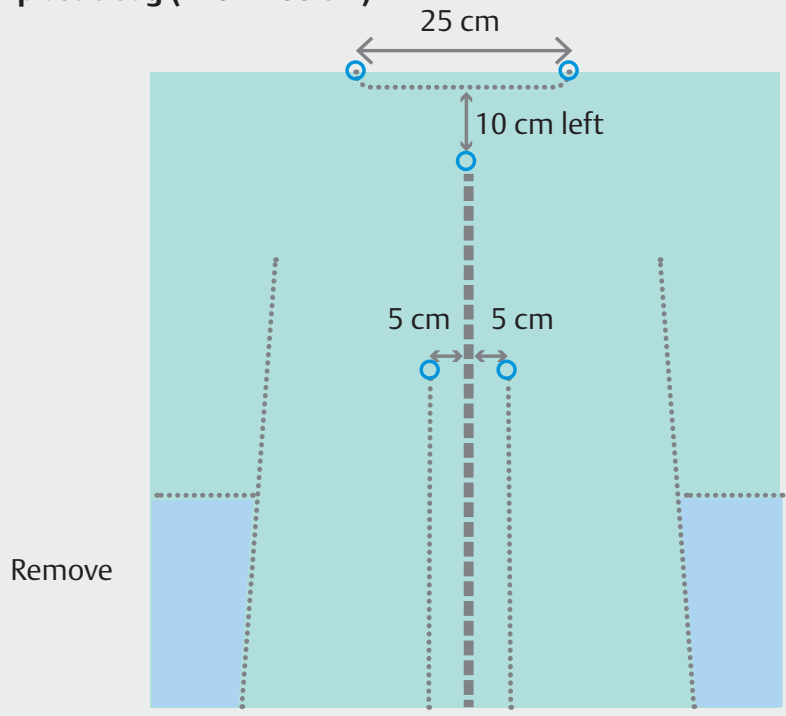

a

\section{Completed gown}

b
Backside of the plastic bag with cutting line

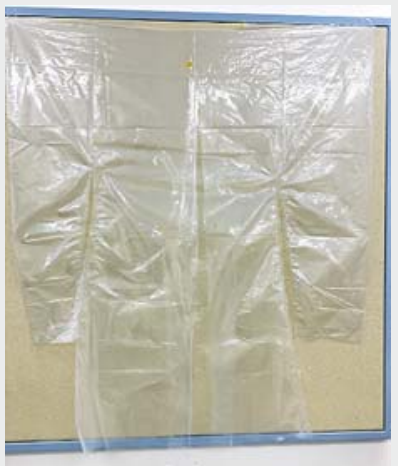

Remove

\section{Bibliography}

DOI https://doi.org/10.1055/a-1197-5949

Published online: 29.6.2020

Endoscopy 2020; 52: E388-E389

(c) Georg Thieme Verlag KG

Stuttgart · New York

ISSN 0013-726X

\section{ENDOSCOPY E-VIDEOS}

https://eref.thieme.de/e-videos

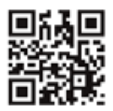

Endoscopy E-Videos is a free access online section, reporting on interesting cases and new

techniques in gastroenterological endoscopy. All papers include a high quality video and all contributions are freely accessible online.

This section has its own submission website at

https://mc.manuscriptcentral.com/e-videos
- Fig. 2 a Cutting lines for a 120 -L plastic bag $(120 \mathrm{~cm} \times 100 \mathrm{~cm})$, back side up; b completed gown.

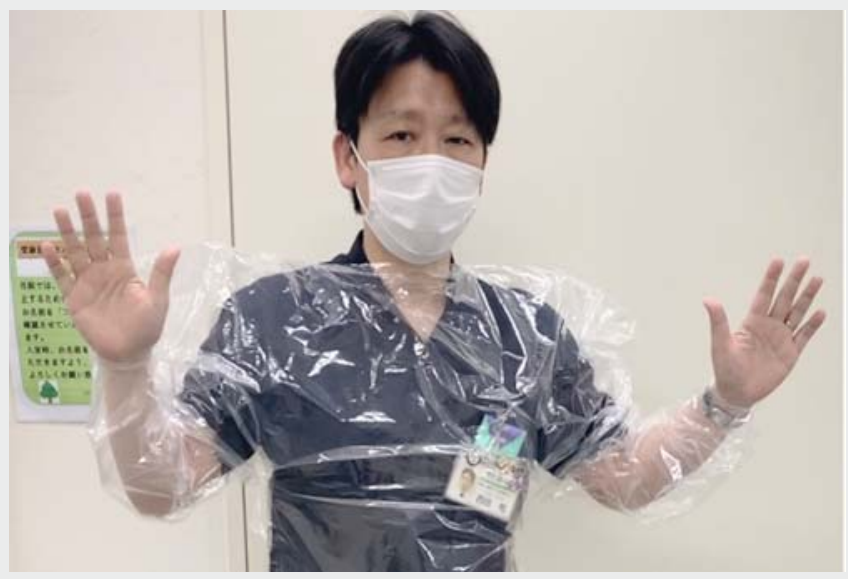

$\checkmark$ Video 1 How to make an alternative long-sleeve plastic gown during the personal protective equipment shortage due to the COVID-19 pandemic: the Toyonaka Poly Gown. 